\title{
Fundulopanchax gardneri Test: A Convenient Method of Bioassay for Active Constituents of Natural Products
}

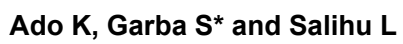

Department of Chemistry, Nigerian Defence Academy, Kaduna, Nigeria

\author{
Abstract \\ Aims: To apply the Brine Shrimp Lethality Test (BST) procedure on locally available Fundulopanchax gadneri \\ killifish with a view to achieving the same result.
}

Study design: Extraction of crude extracts from plants, evaluation of the bioactivity of the extracts using brine shrimp and Fundulopanchax gadneri killifish. Statistical analysis of the results obtained.

Place and duration of the study: Sample: Afaka, Kaduna north local government, Kaduna State, Nigeria. Department of Chemistry, Nigerian Defence Academy, Kaduna. Nigeria, between June 2011 and August 2013.

Methodology: Batch method of extraction, brine shrimp lethality test as adopted by Meyer et al., 1982 using brine shrimp and Fundulopanchax gadneri killifish.

Results: The results of the brine shrimp and Fundulopanchax gadneri killifish bioassay indicate that eleven out of the thirteen medicinal plants screened for bioactivity were active. Statistical analysis of the results showed a correlation coefficient of $0.970,0.99$ and 0.96 respectively for both BST and FGT suggesting that there is a positive correlation between the two variables.

Conclusion: The results are in consonance suggesting that Fundulopanchax gadneri killifish test can be used as a preliminary method of assessing the cytotoxicity of natural products.

Keywords: Bioassay; Brine shrimp lethality test; Fundulopanchax gadneri killifish; Natural products

\section{Introduction}

Over the last decade, interest in drugs of plant origin has been growing steadily. The study of bioactive compounds from plant sources and extracts in the chemical laboratory is often hampered by the lack of a suitable, simple and rapid screening procedure. There are many procedures for bioassay. Collaborative programs with biologists or pharmacologists are required to perform the usual bioassays with whole animals or isolated tissues and organs, as well aseptic techniques in a typical chemical laboratory [1]. When screening for biologically active plant constituents, the selection of the plant species to be studied is obviously a crucial factor for the ultimate success of the investigation. Plants used in traditional medicine are more likely to yield pharmacologically active compounds [2]. The in vivo lethality in a simple zoological organism, such as the Brine Shrimp Lethality Test (BST) [3], might be used as a simple tool to guide screening and fractionation of physiologically active plant extracts. In this type of test the simplest biological responses to monitor is lethality and there is only one criterion: either dead or alive. This general bioassay detects a broad range of biological activities and a diversity of chemical structures. One basic premise here is that toxicology is simply pharmacology at a higher dose. Thus, if we find toxic compounds, a lower, non-toxic dose might elicit a useful, pharmacological perturbation on a physiologic system [4]. Indeed, it has been demonstrated that BST correlates reasonably well with cytotoxic and other biological properties [4] and has been successfully used in various bioassay systems. However, the success recorded in developing countries has been limited by the difficulty in obtaining the brine shrimp eggs and poor storage facilities [5].

Fundulopanchax gardneri Boulenger, 1911 is commonly called Blue Lyretail killifish. The species originates in Nigeria and Cameroun with Nigerian species found in some cities in the northern part of the country. The fish occurs in savannah and rain forest waters. They are very colourful with large eyes and smooth skin. The male is more colourful. This is a characteristic which enables it attract females. The fish measures about $6 \mathrm{~cm}$ long and survives a $\mathrm{pH}$ range of 5-5.7 and a temperature range of $22-24^{\circ} \mathrm{C}$ [6]. F. gardneri can be bred in tank $(50 \mathrm{~cm})$ containing slightly acidic water and some floating plants. The fishes were found abundantly in most of slow running ponds in Kaduna and its environs and are not under the protection of any local law. They were not used as food by the local people as they are considered as fishes growing in dirty and unhealthy environments (Figure 1).

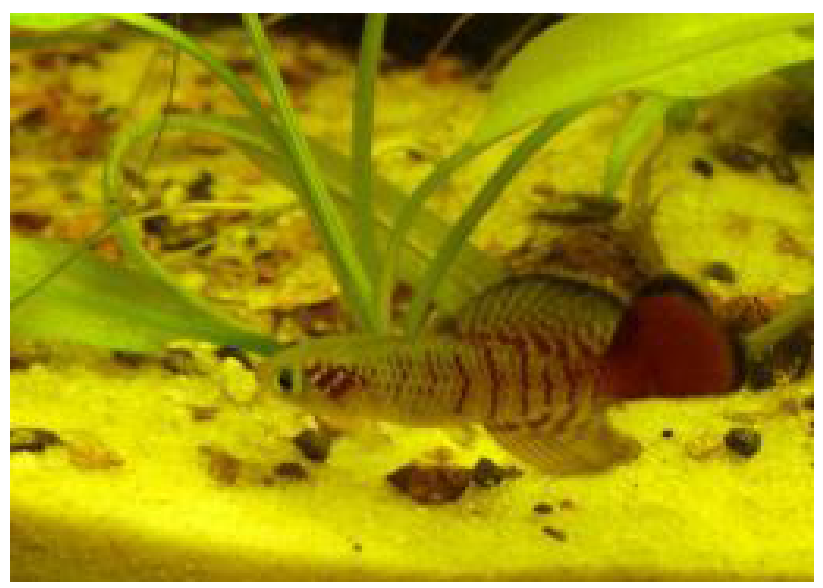

Figure 1: Fundulopanchax gardneri killifish

*Corresponding author: Garba S, Department of Chemistry, Nigerian Defence Academy, Kaduna, Nigeria, E-mail: garsagsai@yahoo.ca

Received March 19, 2014; Accepted April 26, 2014; Published April 28, 2014

Citation: Ado K, Garba S, Salihu L (2014) Fundulopanchax gardneri Test: A Convenient Method of Bioassay for Active Constituents of Natural Products. Nat Prod Chem Res 2 :133. doi: 10.4172/2329-6836.1000133

Copyright: (c) 2014 Ado K, et al. This is an open-access article distributed under the terms of the Creative Commons Attribution License, which permits unrestricted use, distribution, and reproduction in any medium, provided the original author and source are credited. 
In this study, we applied the Brine Shrimp Lethality Test (BST) procedure as adopted by Meyer et al., [3] using locally available Fundulopanchax gardneri killifish with a view to achieving the same result. Methanol, ethyl acetate and n-hexane extracts of plants reported to have medicinal values were subjected to (BST) and Fundulopanchax gardneri Test (FGT) and the results were subjected to statistical analyses to ascertain their concurrence or otherwise.

\section{Materials and Methods}

\section{Sample collection}

The entire plant parts of Schwenkia americana, rhizome of Aristolochia albida, root bark of Cassia arereh, Taminalia mollis, Hymenocardia acida and Carissa edulis, and stem bark of Daniella oliveri, Cussonia arborea, Mangifera indica, Uvaria chamae, Pseudocedrella kotchyii, Tamarindus indica and Nebouldia laevi were collected from Rigachikun, Giwa Local Government Area, Kaduna State, Nigeria. The plants were identified and authenticated by U.S. Gallah of Herbarium Unit, Department of Biology, Ahamdu Bello University, Zaria. The plant materials were air-dried, ground and stored in clean polythene bags at ambient temperature.

\section{Extraction}

A portion $(50 \mathrm{~g})$ each of the respective parts of S. americana, A. albida, C. arereh, T. mollis, H. acida, C. edulis, D. oliveri, C. arborea, $M$. indica, U. chamae, P. kotchyii, T. indica and N. laevis was percolated in $200 \mathrm{~cm}^{3}$ each of methanol, ethyl acetate and n-hexane respectively for 2 weeks. They were separately filtered and evaporated to dryness at $40^{\circ} \mathrm{C}$ using rotary evaporator. Each residue was then allowed to cool, weighed and stored in refrigerator until needed.

\section{Brine Shrimp Lethality Test (BST)}

Fractions obtained were evaluated for lethality to brine shrimp using standard methods [3,4]. In this test a drop of DMSO was added to vials of the test and control substances to enhance the solubility of test materials.

\section{Fundulopanchax gardneri test (FGT)}

A portion $(0.5 \mathrm{~g})$ of each extract was dissolved in $5 \mathrm{~cm}^{3}$ of solvent of extraction to give a stock solution of $100,000 \mu \mathrm{g} / \mathrm{cm}^{3}$. A serial dilution was made by taking $0.5,0.05$ and $0.005 \mathrm{~cm}^{3}$ of the stock solution in to $50 \mathrm{~cm}^{3}$ beaker and allowing them to evaporate. Two drops of DMSO, $25 \mathrm{~cm}^{3}$ of water 10 ( five day old) Fundulopanchax gadneri killifish were added to each beaker and the volume adjusted to $50 \mathrm{~cm}^{3}$ to give approximate concentrations of 1000,100 and $10 \mu \mathrm{g} / \mathrm{cm}^{3}$ respectively. Each test dosage was carried out in triplicate to give a total of 30 Fundulopanchax gadneri killifish per test concentration. These were kept on the bench at ambient temperature for $24 \mathrm{hrs}$. Each beaker was examined and the number of surviving $F$. gardneri fingerlings determined and recorded. A control consisting of 10 F. gardneri, 2 drops of DMSO and water were similarly set up. The concentration that kills $50 \%$ of the test organisms $\left(\mathrm{LC}_{50}\right.$ ) was computed using Finney probit analysis programme [7].

\section{Statistical analysis}

The results obtained were subjected to statistical analysis using mean, standard deviation, correlation coefficient and T-test.

\section{Results and Discussion}

The results of the Brine Shrimp Test (BST) and Fundulopanchax gardneri Test (FGT) for methanol, ethyl acetate and n-hexane extracts are presented in Table 1. With the exception of C. edulis, N. laevis and T. mollis, the results of the methanol and ethyl acetate extracts of the plants indicate very high activities in both tests (BST LC $\mathrm{C}_{50} 3-178 \mu \mathrm{g} / \mathrm{cm}^{3}$ and FGT LC L $_{50} 16-269 \mu \mathrm{g} / \mathrm{cm}^{3}$ ). These results indicate the presence of bioactive compounds that contribute to the overall pharmacological activities of the plants. No activity was observed in the extracts of $N$. laevis in both BST and FGT $\left(\mathrm{LC}_{50}>1000 \mu \mathrm{g} / \mathrm{cm}^{3}\right)$. This showed that although $N$. laevis was reported to be of medicinal values, its active constituents were probably not soluble in all the solvents used for the extractions (Table 1). The n-hexane extracts of the plants were generally found to be inactive (BST and FGT LC L $_{50}>1000 \mu \mathrm{g} / \mathrm{cm}^{3}$ ). This indicates that the active constituents of these plants were not soluble in $n$-hexane except $C$. arereh which exhibited a moderate activity with BST $\mathrm{LC}_{50}$ 355.73 and FGT LC L $_{50} 362.25$ respectively.

A comparison of the activity results obtained from the BST bioassay method showed that the results compared favourably with those obtained from FGT bioassay method (Table 1). Plants extracts whose activities were assessed as very high using BST were equally found to very high using FGT method. In the same vein, extracts that

\begin{tabular}{|c|c|c|c|c|c|c|}
\hline \multirow{3}{*}{ Plant } & \multicolumn{6}{|c|}{ Lethality of extract in solvent (Upper/Lower limit) $95 \%$ Confidence Interval } \\
\hline & \multicolumn{2}{|c|}{ Methanol } & \multicolumn{2}{|c|}{ Ethyl acetate } & \multicolumn{2}{|l|}{ n-Hexane } \\
\hline & BST LC ${ }_{50}\left(\mu \mathrm{g} / \mathrm{cm}^{3}\right)^{*}$ & FGT LC ${ }_{50}\left(\mu \mathrm{g} / \mathrm{cm}^{3}\right)^{*}$ & BST LC ${ }_{50}\left(\mu \mathrm{g} / \mathrm{cm}^{3}\right)^{*}$ & FGT LC ${ }_{50}\left(\mu \mathrm{g} / \mathrm{cm}^{3}\right)^{*}$ & BST LC ${ }_{50}\left(\mu \mathrm{g} / \mathrm{cm}^{3}\right)^{*}$ & FGT LC ${ }_{50}\left(\mu \mathrm{g} / \mathrm{cm}^{3}\right)^{*}$ \\
\hline U. chamae & $3.39(11.67 / 0.07)$ & $27.64(48.96 / 13.37)$ & $54.59(80.84 / 34.73)$ & $62.46(93.71 / 39.47)$ & $106.98(166.20 / 69.24)$ & NA \\
\hline$A$ albida & $40.63(72.63 / 20.14)$ & $66.79(101.03 / 42.12)$ & $114.44(178.42 / 74.27)$ & $140.13(222.26 / 91.81)$ & NA & NA \\
\hline C. arereh & $19.09(33.28 / 9.13)$ & $28.12(43.80 / 18.06)$ & $18.49(30.34 / 10.17)$ & $16.38(25.43 / 9.80)$ & $355.73(452.05 / 125.44)$ & $362.25(521.09 / 245.55)$ \\
\hline P. kotchyii & $42.43(71.97 / 23.47)$ & $29.82(49.54 / 17.24)$ & $63.07(103.96 / 37.51)$ & $73.79(119.36 / 44.99)$ & NA & NA \\
\hline T. indica & $68.78(111.99 / 41.71)$ & $86.74(137.51 / 54.19)$ & $662.92(1153.44 / 422.35)$ & $610.64(1021.15 / 392.66)$ & NA & NA \\
\hline N. laevis & NA & NA & NA & NA & NA & NA \\
\hline C. arborea & $62.46(93.71 / 39.47)$ & $54.59(80.84 / 34.73)$ & $62.46(93.71 / 39.47)$ & $71.42(108.82 / 45.10)$ & NA & NA \\
\hline C. edulis & $196.49(302.94 / 133.64)$ & $296.06(400.72 / 183.08)$ & NA & NA & NA & NA \\
\hline D. oliveri & $66.55(111.96 / 38.02)$ & $71.42(108.83 / 45.10)$ & $52.21(83.06 / 32.52)$ & $66.79(101.03 / 42.12)$ & NA & NA \\
\hline H. acida & $93.48(144.73 / 60.02)$ & $122.41(191.79 / 79.64)$ & $149.72(238.99 / 98.78)$ & $171.24(269.21 / 115.09)$ & NA & NA \\
\hline S. americana & $71.42(108.82 / 45.09)$ & $81.69(126.19 / 51.70)$ & $178.66(289.96 / 111.12)$ & $171.23(269.21 / 115.09)$ & NA & NA \\
\hline T. mollis & $122.41(191.79 / 79.64)$ & $149.72(238.99 / 98.78)$ & NA & NA & NA & NA \\
\hline Mean & 65.59 & 84.58 & 113.05 & 115.34 & 38.56 & 30.19 \\
\hline Stdev & 54.51 & 78.86 & 182.77 & 168.06 & 104.51 & 104.57 \\
\hline Correlation & \multicolumn{2}{|c|}{0.9705619} & \multicolumn{2}{|c|}{0.99789821} & \multicolumn{2}{|c|}{0.95572148} \\
\hline
\end{tabular}

Table 1: Results of BST and FGT bioassays. 
Citation: Ado K, Garba S, Salihu L (2014) Fundulopanchax gardneri Test: A Convenient Method of Bioassay for Active Constituents of Natural Products. Nat Prod Chem Res 2 :133. doi:10.4172/2329-6836.1000133

were assessed as low or moderately active, or even inactive using BST method were similarly assessed using FGT methods.

Table 1 also showed means/standard deviations of both samples and correlation analysis. Correlation value $(\mathrm{r}=0.970,0.99$ and 0.96 $(\mathrm{p}<0.05)$ indicates positive relationship, suggesting lack of significant difference in the performances of the two method employed in the bioassay. The results revealed the proximity of the two bioassay method with respect to their performances.

\section{Conclusion}

The statistical analyses of the BST $\mathrm{LC}_{50}$ and FGT $\mathrm{LC}_{50}$ values suggest that FGT is an efficient bench-top bioassay method. FGT is simple, inexpensive and may be successfully employed as an alternative to the BST in developed countries due to the availability of the resources locally.

\section{Acknowledgement}

Authors acknowledge the contribution of Mr Daniel Ahmedu and all the laboratory technologist of Chemistry Departmental laboratory, Chemistry Department, Nigerian Defence Academy, Kaduna for the contributions towards the success of this research work.

\section{References}

1. Sam TW (1993) Toxicity testing using the brine shrimp: Artemia salina. Bioactive Natural Products 18: 441-456.

2. Hamburger M, Hostettmann K (1991) Bioactivity in plants: the link between phytochemistry and medicine. Phytochemistry 30: 3864-3874.

3. Meyer BN, Ferrigni NR, Putman JE, Jacobson LB, McLaughlin JL (1982) Brine shrimp: A convenient general bioassay for active plant constituents. Planta Medica 45: 31-34.

4. McLaughlin JL (1991) A Novel Mechanism for the Control of Clinical Cancer: Inhibition of the Production of Adenosine Triphosphate (ATP) With a Standardized Extract of paw paw (Asciminicz triloba, Annonaceae). Methods of Plant Biochem 6:1-32.

5. Garba S, Salihu L, Alhaji BB (2009) Aphyoemeon gadneri test (AGT): a preliminary method of assessing the bioactivity of medicinal plants. Nigerian Journal of Scientific Research 8: 30-33.

6. Beansch HA, Riehl R (1982) Aquarium Atlas. J Mergus Verlag Melle, Germany.

7. Finney DJ (1971) Probit analysis (3rd Ed). Cambridge University Press 60 $76-80$ 